\title{
Remote sensing monitoring the spatio-temporal changes of aridification in the Mongolian Plateau based on the general Ts-NDVI space, 1981-2012
}

\author{
Xiaoming $\mathrm{CaO}^{1,{ }^{*}}$ (i), Yiming Feng ${ }^{1}$ and Juanle $\mathrm{WAng}^{2,3}$ \\ ${ }^{1}$ Institute of Desertification Studies, Chinese Academy of Forestry, Beijing 100091, China. \\ ${ }^{2}$ State Key Laboratory of Resources and Environmental Information Systems, Institute of Geographical Sciences \\ and Natural Resources Research, Chinese Academy of Sciences, Beijing 100101, China. \\ ${ }^{3}$ Jiangsu Center for Collaborative Innovation in Geographical Information Resource Development and Application, \\ Nanjing 210023, China. \\ *Corresponding author. e-mail: caoxm@caf.ac.cn
}

MS received 16 June 2016; revised 17 January 2017; accepted 8 February 2017; published online 16 June 2017

This paper has developed a general Ts-NDVI triangle space with vegetation index time-series data from AVHRR and MODIS to monitor soil moisture in the Mongolian Plateau during 1981-2012, and studied the spatio-temporal variations of drought based on the temperature vegetation dryness index (TVDI). The results indicated that (1) the developed general Ts-NDVI space extracted from the AVHRR and MODIS remote sensing data would be an effective method to monitor regional drought, moreover, it would be more meaningful if the single time Ts-NDVI space showed an unstable condition; (2) the inverted TVDI was expected to reflect the water deficit in the study area. It was found to be in close negative agreement with precipitation and $10 \mathrm{~cm}$ soil moisture; (3) in the Mongolian Plateau, TVDI presented a zonal distribution with changes in land use/land cover types, vegetation cover and latitude. The soil moisture is low in bare land, construction land and grassland. During 1981-2012, drought was widely spread throughout the plateau, and aridification was obvious in the study period. Vegetation degradation, overgrazing, and climate warming could be considered as the main reasons.

Keywords. General Ts-NDVI space; aridification; Mongolian Plateau; remote sensing.

\section{Introduction}

In recent decades, the ecological-environment problems in the Mongolian Plateau have become more and more visible, such as the excessive exploitation, utilization and consumption of resources, diverse land use/land cover (LUCC), fragile ecological system, and unfavourable climatic conditions, in which drought has been considered as one of the most serious disasters (Seneviratne et al. 2002; Li et al. 2004; Shu et al. 2011; Shi and Liu 2012). The Mongolian Plateau has been considered to be an important dust source for global dust release (Zhang et al. 1996; Li and Liu 2012). As the largest arid and semi-arid plateau in Northern Hemisphere, the Mongolian Plateau plays an important role in the climate changes and sustainable development of the ecological environment in Northeast Asia and East Asia (Shi and Shen 2002; Wang et al. 2008; Han et al. 2011; Liu et al. 2013; Wang and Feng 2013). The vegetation degradation in the Mongolian Plateau would affect the regional atmospheric circulation (Xue 1996; Liu et al. 2013), temperature-increase in 
north China, temperature-decrease in the central China (Ma et al. 2005), and precipitation-increase in the Yangtz-Huaihe River Basin in China (Zhang et al. 2005; Wang and Feng 2013). Therefore, there have been a number of studies focussed on the climate changes, degradation and drought monitoring in the Mongolian Plateau and its surrounding regions. However, former studies mainly focussed on drought monitor in northwest China (Yang et al. 2011), north China (Bi et al. 2011) and some regions of the Mongolian Plateau (Tian et al. 2012). Studies focussed on the drought variations in the whole Mongolian Plateau have relatively lack of reports.

Drought is a serious disaster, which might turn pastures brown, threaten shrubs and trees, and results in low vegetation cover and high land surface temperature (Ts) (Gao et al. 2011). Soil moisture (SM) is used as a key variable in several applications such as drought severity and duration, soil erosion, etc. (Wang et al. 2004; Xu 2006; Parinaz et al. 2012; Rahimzadeh et al. 2013), and it could be used to monitor the regional drought with water characteristics of strong absorption in shortwave infrared band (Gao et al. 2011). Since the 1980's, various indices, such as normalized difference vegetation index (NDVI) (Tucker et al. 1981; Malo and Nicholson 1990; Anyamba and Tucker 2005; Vicente-Serrano et al. 2006), the vegetation condition index (VCI) (Kogan 1995; Steven and Srinivasan 2010), the normalized difference water index (NDWI) (Mcffters 1996), etc., were developed to investigate vegetation conditions and amount of soil moisture for drought monitoring (Fensholt and Sandholt 2003; Sun et al. 2013; Zhang et al. 2013; Chandrasekar and Sai 2015). However, a single vegetation index (VI) would be easily affected by various natural conditions, and cannot reflect the surface condition comprehensively. A more sensitive indicator is required to develop reflect water stress monitoring (Rahimzadeh et al. 2013). Based on the negative correlation between the Ts and NDVI (Goetz 1997), Sandholt proposed the vegetation index/temperature trapezoid eigen space (VITT) and developed the temperature vegetation dryness index (TVDI) (Sandholt et al. 2002). The follow-up studies simplified VITT as the Ts-NDVI triangle space (the Ts-NDVI space) to express the negative correlation more clearly (figure 1) (Price 1990; Carlson 2007; Liu et al. 2008). Researchers have monitored regional soil moisture using TVDI based on various remote sensing data, such as AVHRR (Rhee et al. 2010; Huber and Fensholt
2011), MODIS (Chen et al. 2006; Caccamo et al. 2011), Lansat TM (Gao et al. 2011), and so on.

The Ts-NDVI space is easily affected by many factors, such as soil moisture, vegetation cover, quality of remote sensing data, and so on, which may lead to large differences in different periods, including the unstable dry/wet edges, and could not clearly express the theoretical edges of the space (Rahimzadeh et al. 2012). Moreover, Sun and Kafatos (2007) pointed that the obvious negative relationship between NDVI and Ts only happens in the growing seasons and not in winter. Thus, a stable Ts-NDVI space is required for a long-term regional drought monitoring. However, studies on the long-term regional soil moisture monitoring mainly focused on the models established by the remote sensing data in single time, or the comparison of a variety of drought index (Gao et al. 2011; Dogan et al. 2012; Du et al. 2013). Yu et al. (2011) suggested that if the vegetation did not change greatly, based on years of remote sensing data, the general Ts-NDVI space could be established, which would provide a more stable dry/wet edges, and the edges would be more closest to the theoretical edges.

Based on the long-term remote sensing data of AVHRR NDVI and MODIS NDVI from 1981 to 2012, a general Ts-NDVI space was developed to estimate soil moisture in the Mongolian Plateau. Based on the soil moisture site data and precipitation data, the accuracy of the inverted results was analyzed. Moreover, the spatio-temporal variations of the TVDI were studied; then, the spatiotemporal variations of aridification, and aridification in different land use/land cover (LUCC) in the Monglian Plateau were deeply explored.

\section{Materials and methodologies}

\subsection{Study area}

The Mongolian Plateau $\left(87^{\circ} 40^{\prime}-122^{\circ} 15^{\prime} \mathrm{N}, 37^{\circ} 46^{\prime}-\right.$ $\left.53^{\circ} 08^{\prime} \mathrm{E}\right)$ is the largest arid and semi-arid plateau in the Northern Hemisphere. The elevation decreases gradually from west to east, with an average value of $1580 \mathrm{~m}$. The annual precipitation is $\sim 300$ $400 \mathrm{~mm}$, and it decreases from north to south and east to west. In south Mongolia, the annual precipitation is almost $<200 \mathrm{~mm}$. The vegetation cover from north to south consists of forest, forest steppe, typical steppe, desert steppe and the 


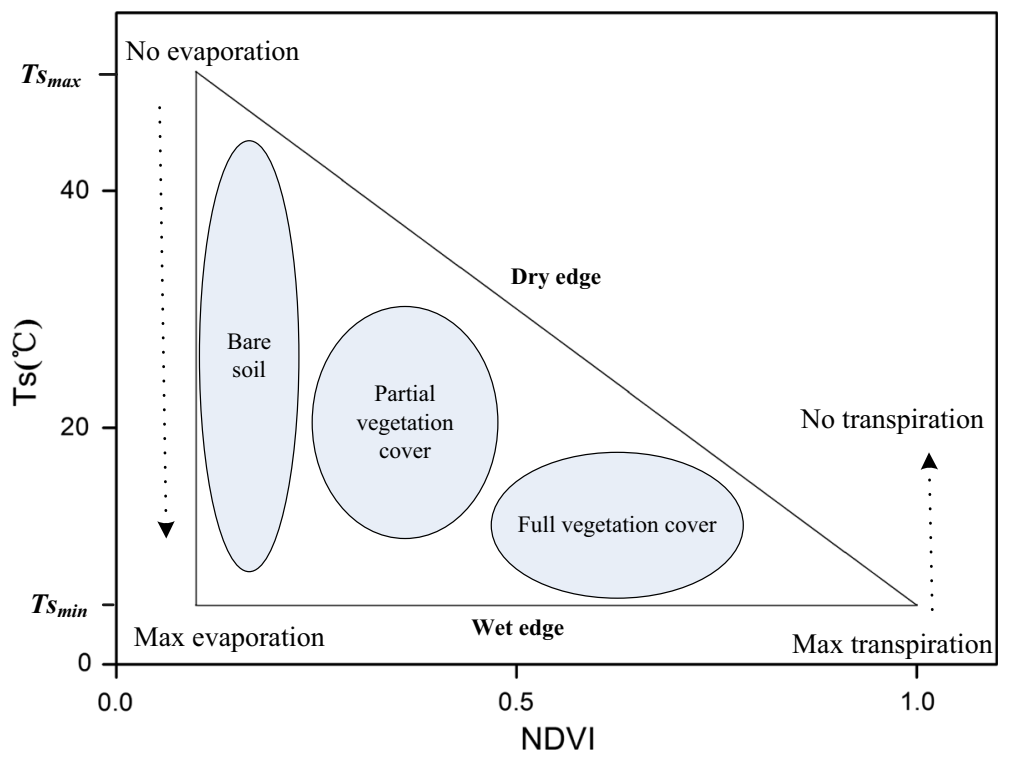

Figure 1. The NDVI-Ts triangle space (Sandholt et al. 2002).

Gobi desert. The study area contains the Inner Mongolia Autonomous Region, Mongolia and the Tuva Republic, for which the total area is about $297.36 \times 10^{4} \mathrm{~km}^{2}$ (figure 2).

\subsection{Data and reprocessing}

\subsubsection{Remote sensing data}

AVHRR 8-km NDVI composites

The 10-d 'Twenty-year Global 4-minute AVHRR NDVI Dataset' (8 km) (July 13, 1981-December 21, 1999) were obtained from Chiba University. The composites included five channels, the 10-d NDVI dataset was calculated from the 1st and 2nd channels (Holben 1986; Cihlar and Huang 1997).

$$
\mathrm{NDVI}=1000 \times(b 2-b 1) /(b 2+b 1)
$$

where $b 1$ and $b 2$ are the 1st and 2nd channels of the AVHRR dataset.

The 10-d Ts dataset was calculated from the 4th and 5th thermal infrared channels by splitwindow algorithms (Becker and Li 1990; Sobrino et al. 1991; Cihlar et al. 1997).

- MODIS/Terra NDVI products MODIS/Terra NDVI products $(1 \mathrm{~km}$ MOD11A2 and $1 \mathrm{~km}$ MOD13A2) were obtained from the EOS data Gateway (NASA-EOS 2006). The MOD11A2 product (global 8-d $1 \mathrm{~km}$ surface temperature/ emissivity data) covers the period from the 65th day, 2000 to the 353rd day, 2012. The MOD13A2 product (global $1 \mathrm{~km}$ 16-d vegetation index data) covers the period from the 49th day, 2000 to the 353rd day, 2012. To unify the temporal resolution, the 16-d surface temperature/emissivity data were calculated from the mean values of the $8-d$ data.

\subsubsection{Measured soil moisture dataset}

The 10-d measured soil moisture dataset was obtained from the China Meteorological Science Data Sharing Service (http://cdc.cma.gov.cn/home. do). The dataset included the $10-\mathrm{cm}$ relative soil moisture of the agro meteorological stations in the Inner Mongolian Autonomous Region from January 1992 to October 2012.

\subsubsection{The land use/land cover data}

The land use/land cover (LUCC) data $(500 \mathrm{~m})$ of 2001, 2005 and 2009 were collected from the National Science and Technology Basic Conditions Platform, Earth System Science data sharing platform. The classification accuracy is higher than 78\% (http://www.geodata.cn/). The main LUCC types were forest, shrub land, grassland, cropland, bare land, construction land, wet land, and others (water area) (figure 3).

\subsubsection{The observed meteorological data}

The observed meteorological data (1981-2010), including the monthly precipitation data, was obtained from the World Meteorological 


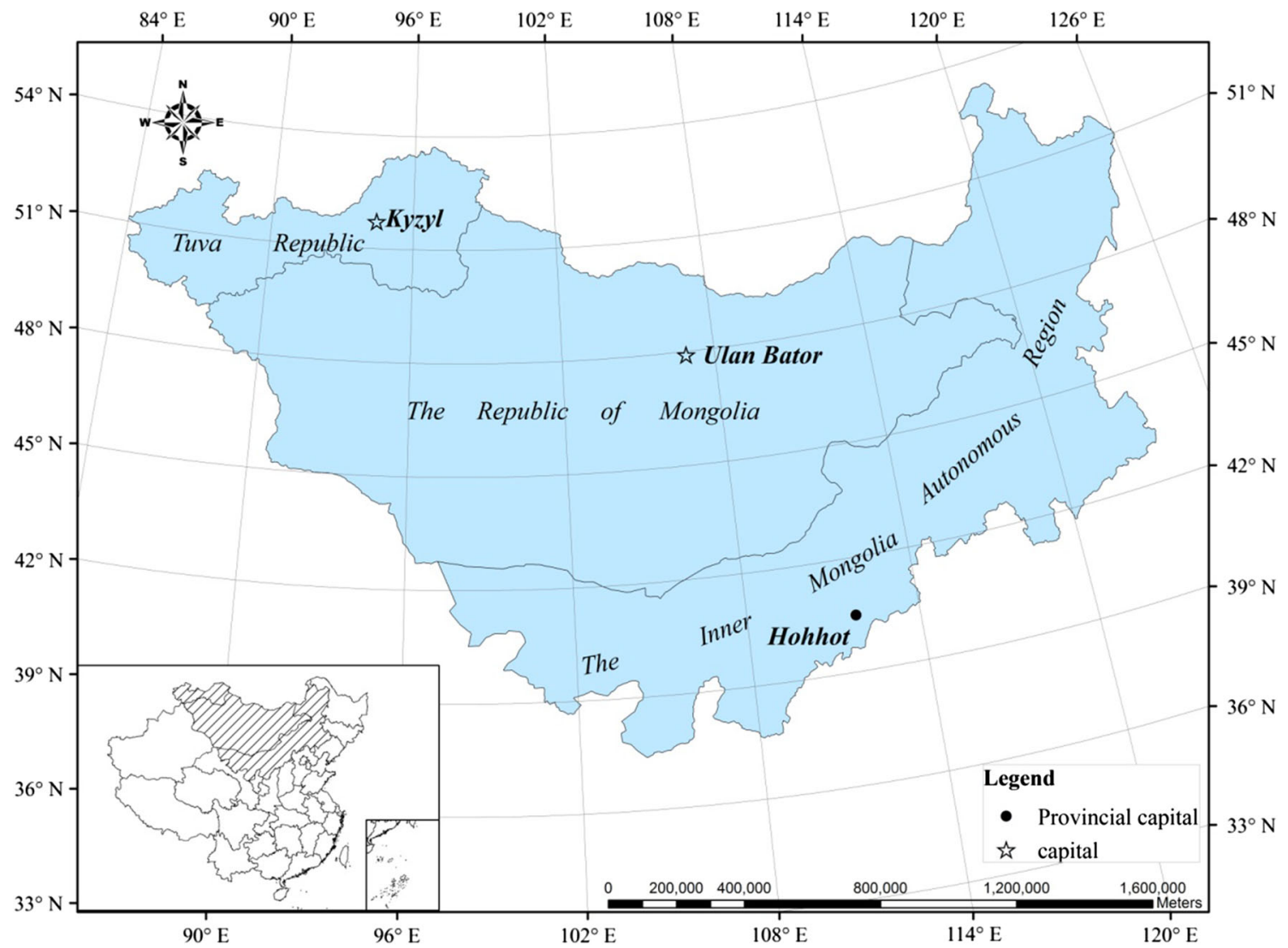

Figure 2. The study area.

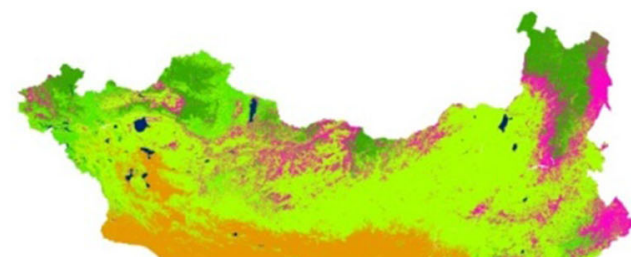

(a) 2001

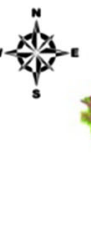

(b) 2005
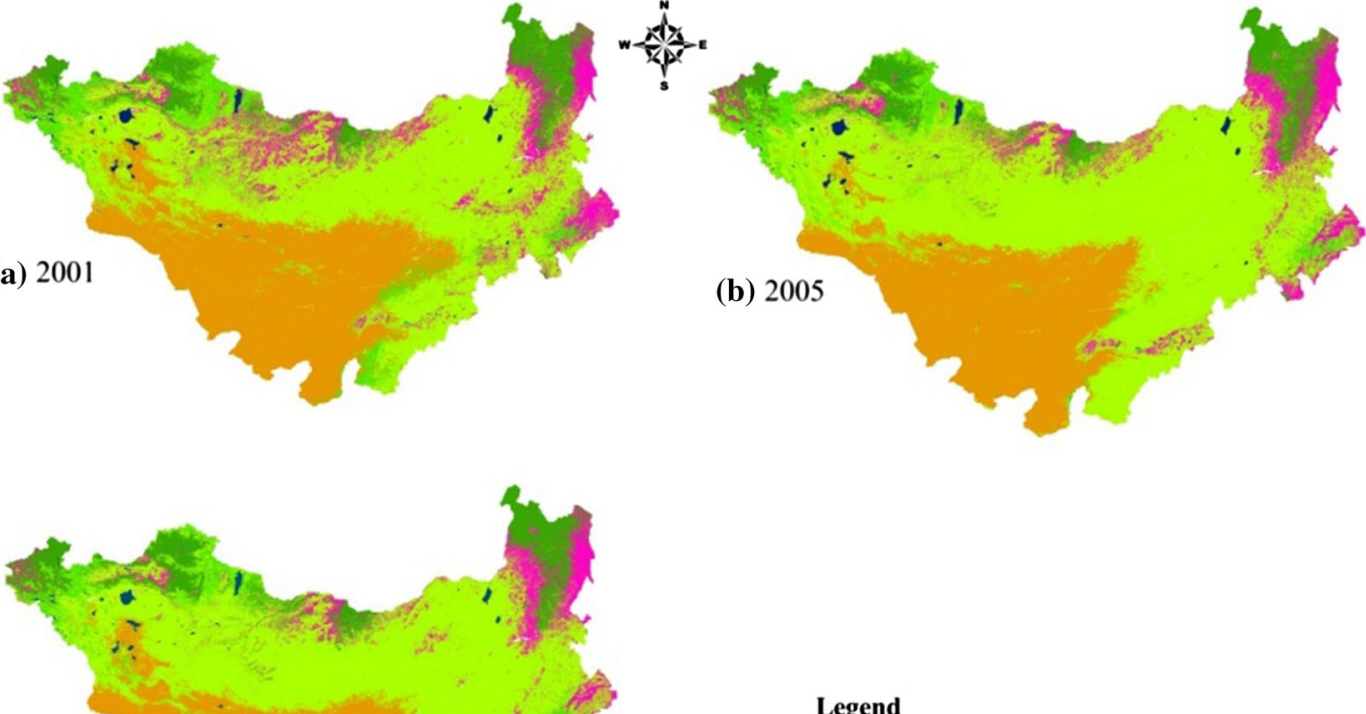

(c) 2009

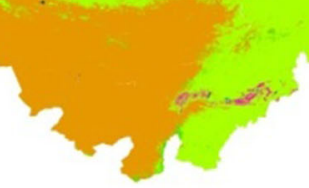

$$
\begin{aligned}
& \text { Legend } \\
& \text { Forest Bare land } \\
& \text { Shrub land Construction land } \\
& \square \text { Grassland Wet land } \\
& \text { Cropland Others }
\end{aligned}
$$

\begin{tabular}{l}
$0 \quad 437,500875,000 \quad 1,750,000$ \\
\hline
\end{tabular}

Figure 3. The land use/land cover (LUCC) in the Mongolia Plateau in 2001, 2005 and 2009. 
Organization (WMO) World Weather Watch Program. There were about 60 meteorological stations available in the Mongolian Plateau. The annual precipitation data was the cumulative precipitation of the growing season (April-October).

\subsection{The methodologies}

\subsubsection{The comparison of the AVHRR NDVI composites and MODIS/Terra NDVI products}

Both AVHRR dataset and the MODIS dataset were widely used in the large scale monitoring of surface ecological environment and vegetation (Yu et al. 2010). Although, there are respective advantages of the two datasets in these largescale studies, there would be more profound study of the combination with the two datasets (Liu et al. 2012). Due to different spatial resolutions of the two datasets, consistency evaluation would be needed for the long-term analysis (Gallo et al. 2004; Frey et al. 2012).

Based on the data of the overlapping period (2000-2001), the linear regression models of the two datasets were established using the annual maximum, mean and minimum NDVI/Ts values during April-October. The moving window of $8 \times 8$ MODIS pixels was used to get the mean NDVI and Ts values from the two datasets to establish the model. Figure 4 presents the two-dimensional (2D) histogram plots of AVHRR NDVI and MODIS NDVI (figure 4a), AVHRR Ts and MODIS Ts (figure $4 \mathrm{~b}$ ). A comparison of the plots shows that there is good linear relationship in the NDVI and Ts scatter plots of the two datasets, and the samples distributed were near to the ratio $1: 1$. The $R^{2}$ of the NDVI and Ts value for two datasets was 0.960 $(P<0.01)$ and $0.963(P<0.01)$. The relationship between the two datasets was as follows:

$$
\text { AVHRR NDVI }=0.912 \times \text { MODIS NDVI }+0.020
$$

AVHRR Ts $=0.979 \times$ MODIS Ts +1.766.

\subsubsection{The establishment of the general Ts-NDVI space}

Sandholt et al. (2002) pointed that Ts would be affected by many factors, such as soil moisture, evapotranspiration, the net radiation absorbed by the land surface, etc., but the effects from soil moisture and evapotranspiration would be larger than that from other factors under certain geographical climatic and atmospheric conditions. For a study area, if the total vegetation cover maintains in a stable level for many years, the general NDVI-Ts triangle space could be combined based on the years of remote sensing data over the same period. This method could improve the stability of the traditional Ts-NDVI space established by one single satellite data, which would be more suitable for a long-term soil moisture monitoring study.

The combination steps of the general Ts-NDVI space are as follows (figure 5). (1) for a period of observation, the annual Ts-NDVI space was
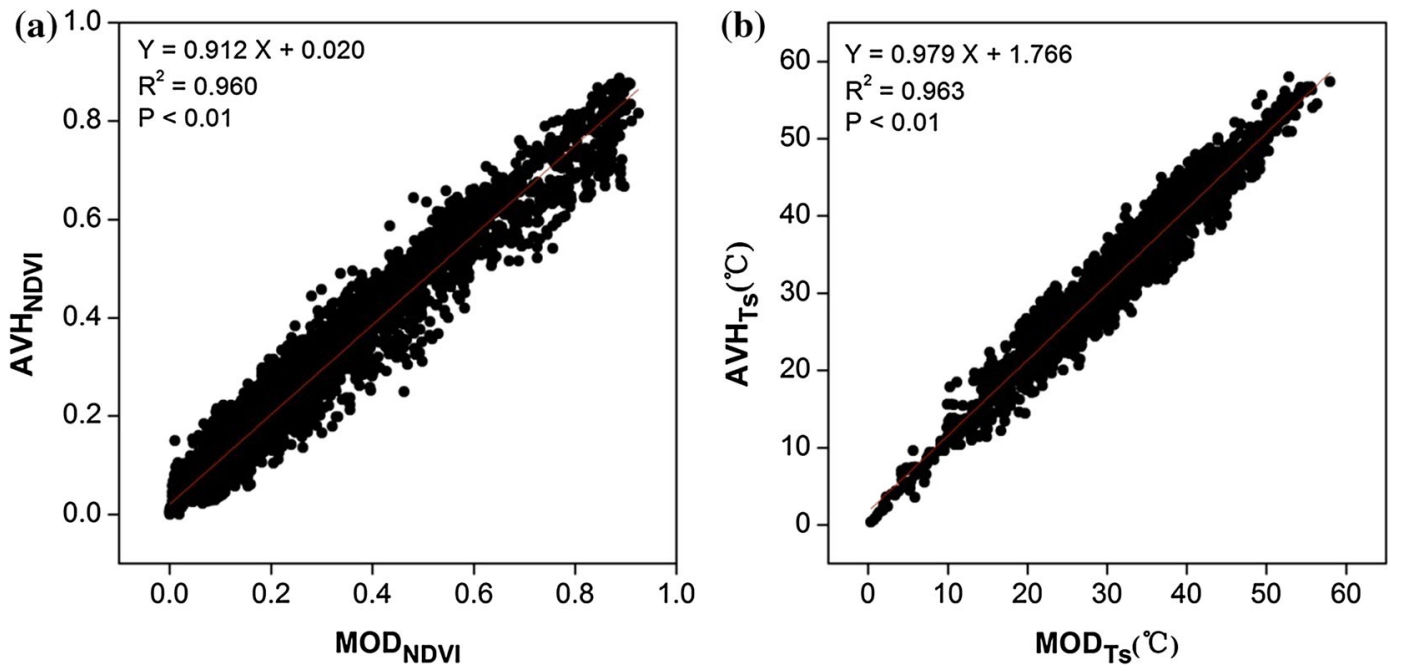

Figure 4. The comparison of (a) NDVI and (b) Ts between AVHRR dataset and MODIS dataset (MOD means the MODIS NDVI dataset, and AVH means the AVHRR NDVI dataset). 


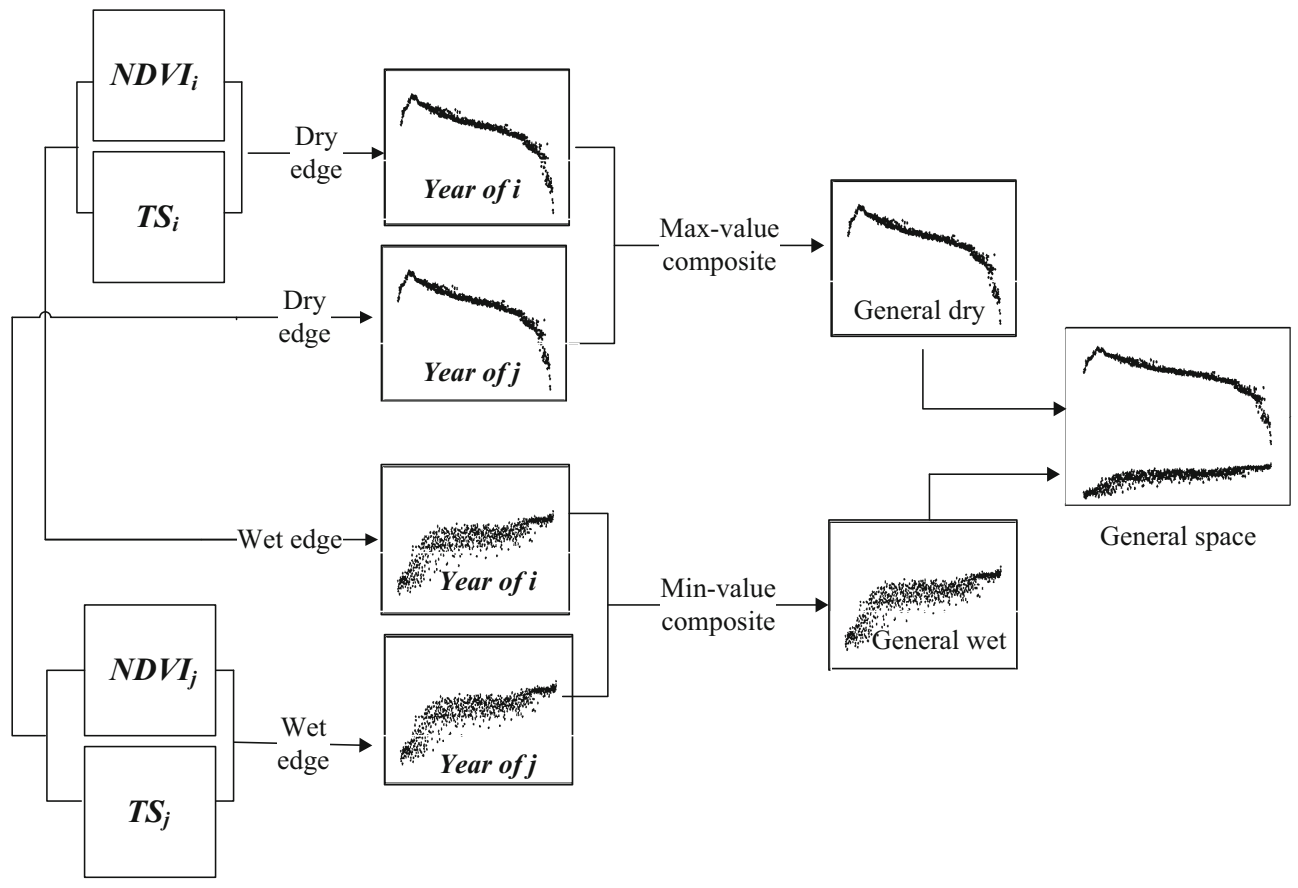

Figure 5. Flow chart composing the general Ts-NDVI space.

extracted by the remote sensing data of every year with small intervals of NDVI value (0.001), the corresponding maximum or minimum Ts for every NDVI value was respectively obtained by using the maximum value composite method or the minimum value composite method. The dry edge was constituted by the maximum Ts values, and the wet edge was constituted by the minimum Ts values. (2) The combination of the general TsNDVI space with the same interval NDVI value (0.001), by using the maximum value composite method or the minimum value composite method, the perennial maximum or minimum Ts for every NDVI value was respectively obtained from the Ts value in the dry or wet edge extracted above. The general dry edge was constituted by the perennial maximum Ts values, and the general wet edge was constituted by the perennial minimum Ts values. They were calculated by the equations as follows:

$$
\begin{aligned}
& T s_{\text {wet }_{i}}=a_{1}+b_{1} \times I_{N D V I_{i}} \\
& T s_{d r y_{i}}=a_{2}+b_{2} \times I_{N D V I_{i}}
\end{aligned}
$$

where $I_{N D V I_{i}}$ was the NDVI value of the pixel $i$; $T s_{\text {wet }_{i}}$ was the corresponding minimum $T s$ value of very NDVI value (wet edge); $T s_{d r y_{i}}$ was the corresponding maximum $T s$ value of very NDVI value (dry edge); $a_{1}, a_{2}, b_{1}, b_{2}$ respectively means the intercepts and the slopes of the wet and dry edges in the general Ts-NDVI space.

\subsubsection{Definition of the temperature vegetation dryness index}

Providing the design basis for VITT, different vegetation index, such as NDVI, ANDVI (the Airborne Normalized Difference Vegetation Index), MSAVI (the Modified Soil-adjusted Vegetation Index) and SAVI (the Soil-adjusted Vegetation Index) may have different relationships with Ts (Heim 2002; Keyantash and Dracup 2002). Sandholt et al. (2002) reported that the simplified Ts-NDVI triangle space may exhibit the soil moisture contours reflecting the spatial patterns of the VITT, which led to the definition of the TVDI as expressed below

$$
\mathrm{TVDI}=\frac{T s-T s_{w e t}}{T s_{d r y}-T s_{w e t}}
$$

where $T s_{d r y}$ was the corresponding maximum $T s$ value of very NDVI value (dry edge), $T s_{\text {wet }}$ was the corresponding minimum $T s$ value of very NDVI value (wet edge).

\subsubsection{The slope of TVDI}

Linear regression analysis could be used to analyze the change in every grid. Stow et al. (2003) have used this method to estimate the Greenness Rate of Change (GRC). This study used this method to 

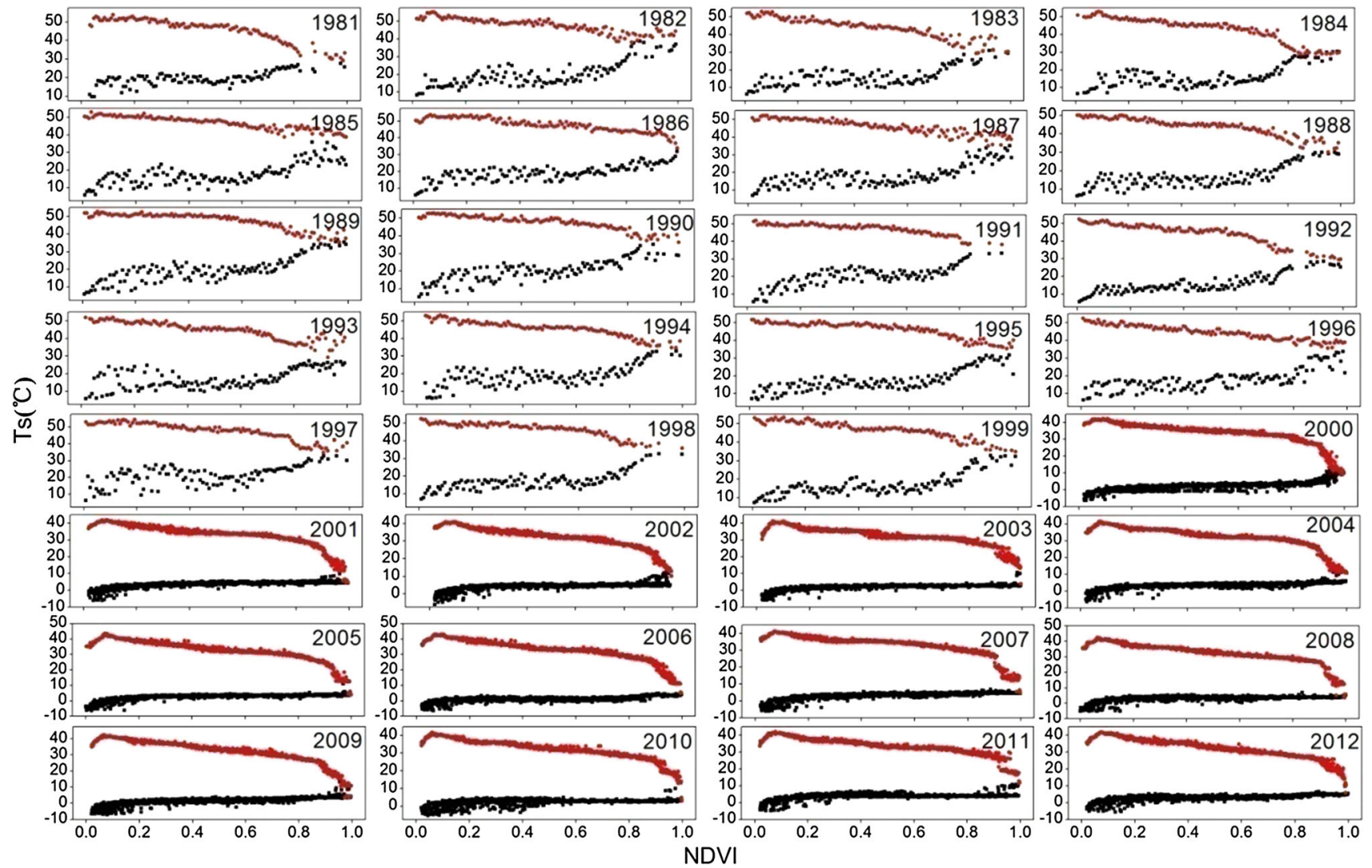

Figure 6. The single time NDVI-Ts triangle space of every year.

simulate the multi-annual variation trends of the TVDI. The formula was

$$
\Theta_{\text {slope }_{T V D I}}=\frac{\begin{array}{c}
n \times \sum_{i=1}^{n} i \times T V D I_{i} \\
-\sum_{i=1}^{n} i \sum_{i=1}^{n} i \times T V D I_{i}
\end{array}}{\sum_{i=1}^{n} i^{2}-\left(\sum_{i=1}^{n} i\right)^{2}}
$$

where $i$ is the year, TVDI $i$ is the mean TVDI of the year $i$. The linear regression trend line was the whole multi-annual change trend of the simulated TVDI. The confidence level of the regression equation was significant (95\%). The regression trend line described the changes occurring during the study period. If $\Theta_{\text {slope }}>0$, TVDI during the study period increased, and vice versa.

\section{Results and discussion}

\subsection{The application evaluation of the general Ts-NDVI space}

\subsubsection{The improvement of the Ts-NDVI space}

Considering the different spatial resolutions of two datasets, the general Ts-NDVI space for 1981-1999 and 2000-2012 was established respectively. It should be pointed out that, the data assimilation of the two datasets has been processed before the TVDI was inverted according to equations (2 and 3 ). The results indicated that, compared to the general Ts-NDVI spaces (figure 7), the single time Ts-NDVI spaces showed some instabilities (figure 6). It means that there were quite a lot of differences among the dry/wet edges in the different years. Taking the years of 1986, 1997, 2002 and 2008, for example, the dry edge and wet edge were closer (figure 6), but in the general Ts-NDVI space, the dry edges in these years were much different from the wet edges (figure 7). Moreover, in the single time spaces, there were some points with abnormal lower values scattering outside the wet edge, which would reduce the fitting accuracy. This phenomenon obviously occurred in the single time spaces during 1981-1999. It may be resulted from the low spatial resolution of AVHRR datasets and less samples extracted in the wet edges.

According to the combination methods in section 2.3.2, because of the use of the maximum and minimum value composite of $\mathrm{Ts}$, in the general Ts-NDVI spaces, the Ts values in dry edges 

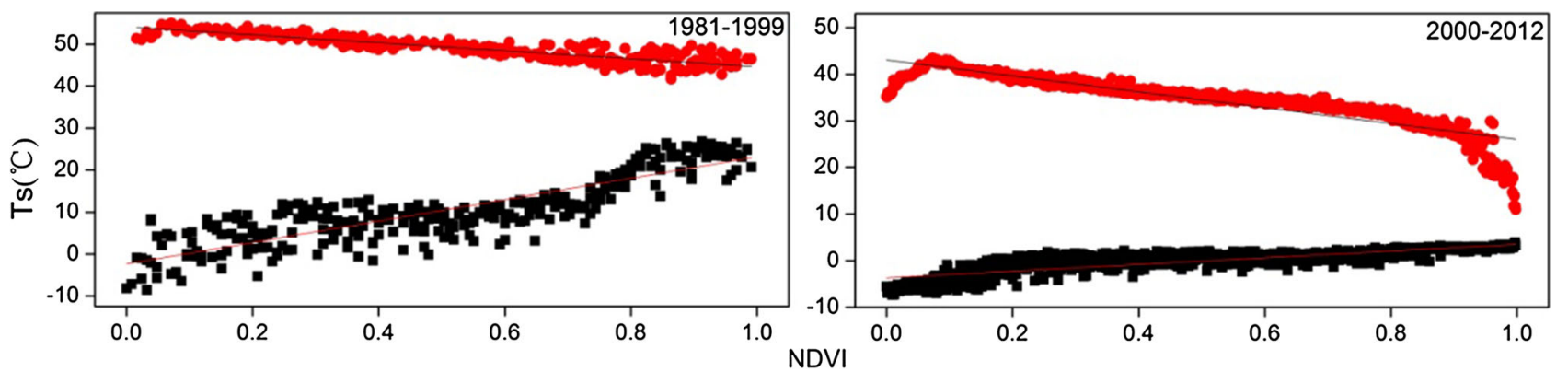

Figure 7. The general Ts-NDVI triangle space.

Table 1. The linear correlation coefficients between the TVDI based on the single time/ general Ts-NDVI space and the measured 10-cm soil moisture.

\begin{tabular}{llllllll}
\hline Year & 1992 & 1993 & 1994 & 1995 & 1996 & 1997 & 1998 \\
\hline Number of samples & 30 & 31 & 81 & 74 & 38 & 77 & 48 \\
$R^{2}$ of the general space & 0.510 & 0.442 & 0.545 & 0.516 & 0.452 & 0.511 & 0.417 \\
$R^{2}$ of the single time space & 0.499 & 0.403 & 0.542 & 0.514 & 0.456 & 0.450 & 0.413 \\
\hline Year & 1999 & 2000 & 2001 & 2002 & 2003 & 2004 & 2005 \\
\hline Number of samples & 64 & 49 & 66 & 74 & 99 & 90 & 116 \\
$R^{2}$ of the general space & 0.637 & 0.345 & 0.653 & 0.435 & 0.513 & 0.406 & 0.525 \\
$R^{2}$ of the single time space & 0.600 & 0.346 & 0.649 & 0.356 & 0.511 & 0.408 & 0.520 \\
\hline Year & 2006 & 2007 & 2008 & 2009 & 2010 & 2011 & 2012 \\
\hline Number of samples & 67 & 106 & 77 & 109 & 65 & 104 & 122 \\
$R^{2}$ of the general space & 0.361 & 0.510 & 0.403 & 0.465 & 0.432 & 0.570 & 0.477 \\
$R^{2}$ of the single time space & 0.358 & 0.498 & 0.321 & 0.461 & 0.429 & 0.567 & 0.453 \\
\hline
\end{tabular}

were commonly higher, and the Ts values in wet edges were commonly lower than that in the single time spaces. In addition, the number of abnormal samples also reduced significantly, and the boundaries of the general Ts-NDVI spaces were more clear than those of the single time spaces (figures $6,7)$.

\subsubsection{The correlation between the inverted TVDI and the measured 10-cm soil moisture}

The 10-cm measured soil moisture (10-d) ground validation data acquired in the study were the station data. To match the time resolution of remote sensing dataset, the measured 10-d soil moisture data was interpolated as the 16-d time series data. To match the spatial resolutions of the remote sensing data, the pixels with the NDVI variance $<0.005$ and the Ts variance $<2^{\circ} \mathrm{C}$ were obtained by the $3 \times 3$ pixels window. The mean TVDI values in the $3 \times 3$ pixels window were calculated to establish the linear relationship with the measured soil moisture data.
Table 1 shows a significant negative relationship between inverted TVDI and the measured 10$\mathrm{cm}$ soil moisture every year, which indicates that TVDI could be chosen as a suitable indicator to monitor drought and aridification. The results show that in 1993, 1997, 2002 and 2008, the correlations in the general Ts-NDVI spaces were better than that in the single time spaces, but there were no obvious differences of the correlation in other years (table 1). It could be explored that, in the above mentioned years, the Ts in dry/wet edges in the general spaces was obviously different from that in the single time spaces (figures 6,7 ). It would be included that, if the dry/wet edge in the single time space is obviously different from that in the general space, the general space extracted from years of remote sensing data would be more stable, and the inverted results of the general space would also be more meaningful and closer to the theoretical value. Otherwise, the single time space shows perfect structure, there would be no differences between the inverted results of the single time space and the general space. 
Table 2. The linear correlation coefficients between the TVDI based on the single time/general Ts-NDVI space and the cumulative precipitation.

\begin{tabular}{lcccccccc}
\hline Year & 1981 & 1982 & 1983 & 1984 & 1985 & 1986 & 1987 & 1988 \\
\hline$R^{2}$ of the general space & 0.506 & 0.479 & 0.487 & 0.504 & 0.531 & 0.458 & 0.527 & 0.496 \\
$R^{2}$ of the single time space & 0.487 & 0.481 & 0.476 & 0.493 & 0.528 & 0.325 & 0.482 & 0.398 \\
\hline Year & 1989 & 1990 & 1991 & 1992 & 1993 & 1994 & 1995 & 1996 \\
\hline$R^{2}$ of the general space & 0.473 & 0.509 & 0.521 & 0.525 & 0.477 & 0.467 & 0.515 & 0.495 \\
$R^{2}$ of the single time space & 0.471 & 0.496 & 0.499 & 0.521 & 0.452 & 0.461 & 0.502 & 0.496 \\
\hline Year & 1997 & 1998 & 1999 & 2000 & 2001 & 2002 & 2003 & 2004 \\
\hline$R^{2}$ of the general space & 0.453 & 0.478 & 0.513 & 0.469 & 0.451 & 0.472 & 0.489 & 0.513 \\
$R^{2}$ of the single time space & 0.368 & 0.475 & 0.510 & 0.452 & 0.446 & 0.435 & 0.465 & 0.506 \\
\hline Year & 2005 & 2006 & 2007 & 2008 & 2009 & 2010 & & \\
\hline$R^{2}$ of the general space & 0.484 & 0.507 & 0.533 & 0.466 & 0.481 & 0.488 & & \\
$R^{2}$ of the single time space & 0.477 & 0.506 & 0.529 & 0.432 & 0.459 & 0.489 & & \\
\hline
\end{tabular}

The results show that, there was an obvious inter-annual changes of the correlations between the inverted TVDI and the measured $10 \mathrm{~cm}$ soil moisture. It would have resulted from the high difference in the spatio-temporal resolutions between remote sensing data and the measured $10 \mathrm{~cm}$ soil moisture data. Although, the time interpolation and spatial buffer has been processed, the differences could not be eliminated completely. In addition, the differences of the atmospheric conditions, the sun angle, and the observation angle of remote sensing data in different years also affect the monitoring results.

\subsubsection{The correlation between the inverted TVDI and the cumulative precipitation}

The measured precipitation data were also station data. To match the spatial resolutions of the remote sensing data, the pixels with the TVDI variance $<0.005$ and the Ts variance $<2^{\circ} \mathrm{C}$ were obtained by the $3 \times 3$ pixels window. The mean TVDI values in the $3 \times 3$ pixels window were calculated to establish the linear relationship with the measured cumulative precipitation (April-October). The results show an obvious negative relationship between TVDI and the cumulative precipitation $(R>0.65, P>0.5)$ (table 2$)$. It would be revealed that, when the annual precipitation is low $(<400 \mathrm{~mm})$, the degree of drought would be determined by precipitation. Studies also revealed that, in the regions with high precipitation, besides precipitation, other factors affecting the regional energy and water balance would also influence the occurrence of drought (Qi 2004).
Table 2 shows that in 1981, 1986, 1993, 1997, 2002 and 2008, the correlations in the general TsNDVI space were better than that in the single time spaces, but there were no obvious differences of the correlation in other years, which would indicate the similar results mentioned in section 3.1.2 if the dry/wet edge in the single time space is obviously different from that in the general space, the general space extracted from years of remote sensing data would be more stable, and the inverted results of the general space would also be more meaningful and closer to the theoretical value. In addition, the correlations between the inverted TVDI and the cumulative precipitation also showed major inter-annual fluctuations, which would result from the influence of the quality and the atmospheric condition for the satellite observation.

\subsection{The spatio-temporal development of the aridification}

\subsubsection{The spatial development of the aridification}

The inverted TVDI in the study was classified into five levels (table 3) (Qi 2004). Figure 8 shows that TVDI could reflect the spatio-temporal changes of drought in the Mongolian Plateau. TVDI in the Mongolian Plateau changed according to the changes in vegetation types, vegetation coverage and latitude. It decreased in the areas with higher latitude, higher vegetation cover or well-growing vegetation, which would indicate higher soil moisture and little drought events in these areas; in opposite, the soil moisture would be possibly lower 
Table 3. TVDI classification standard of drought in the Mongolia Plateau.

\begin{tabular}{|c|c|c|c|c|c|}
\hline & \multicolumn{2}{|c|}{ The humid area } & \multirow{2}{*}{$\begin{array}{c}\text { The normal area } \\
\text { Normal }\end{array}$} & \multicolumn{2}{|c|}{ The arid area } \\
\hline & Extremely wet & Wet & & Dry & Extremely dry \\
\hline The classification of TVDI & {$[0,0.2]$} & {$[0.2,0.4]$} & {$[0.4,0.6]$} & {$[0.6,0.8]$} & {$[0.8,1.0]$} \\
\hline
\end{tabular}

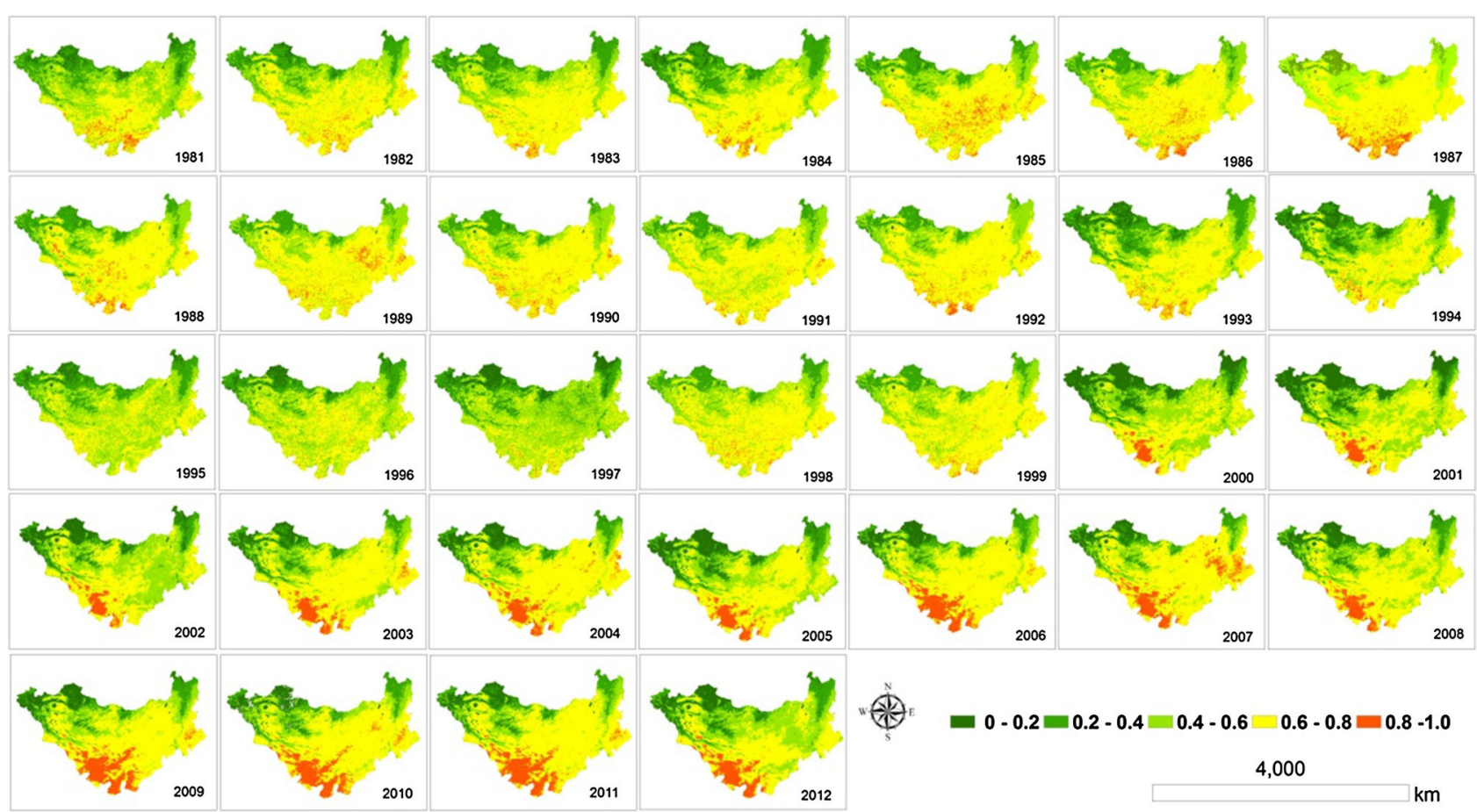

Figure 8. The spatial distribution of the annual TVDI during 1981-2012.

in the regions with lower latitude, lower vegetation cover or poorly-growing vegetation, indicating frequent drought events in these areas (figure 8). Most of the plateau was covered by the extremely dry and dry levels, the same conclusion would be found in some earlier studies (Guo 2010; Bi et al. 2011). The extremely dry level was mainly distributed in the southwest Mongolian Plateau, where the vegetation cover mainly decreased (Bao et al. 2013); the dry level was mainly distributed in the middle and northeast plateau, where also the degradation occurs; the extremely wet and wet levels mainly distributed in the north plateau. Overall, drought was widely spread in the Mongolian Plateau, which would mainly result from the dry climate and low covered vegetation.

Concerning the three administrative regions in the study area, the wet and extremely wet levels mainly distributed in the Greater Khinggan Mountains in inner Mongolia, the eastern and western regions in the Tuva Republic, and the north Mongolia. The normal level mainly distributed in the higher vegetation-covered grassland in the north and west Mongolia, the surrounding areas of the Greater Khinggan Mountains, and the cropland in the mid-east Inner Mongolia. The extremely dry and dry levels mainly distributed in the south Mongolia, the east, west and middle Inner Mongolia. There were close relationship among the spatial distribution in drought, climatic zone and precipitation. The low precipitation, high temperature in the summer, and the low temperature in the longterm winter may also lead to the widely spread drought in the plateau.

Figure 9 shows that the soil moisture decreased in the west Tuva, the west and north Mongolia, the southeast inner Mongolia and increased mainly in the south Mongolia, the south and southwest inner Mongolia, and the cropland during east inner Mongolia. In the Greater Khinggan Mountains, the soil moisture increased during 1990-1999, but decreased in 1981-1989 and 2000-2012. Tong et al. (2014) also pointed that, there was good vegetation growth in 1990-1999, and poor vegetation growth in 1982-1989. During the period of 19812012, the soil moisture decreased continuously in 


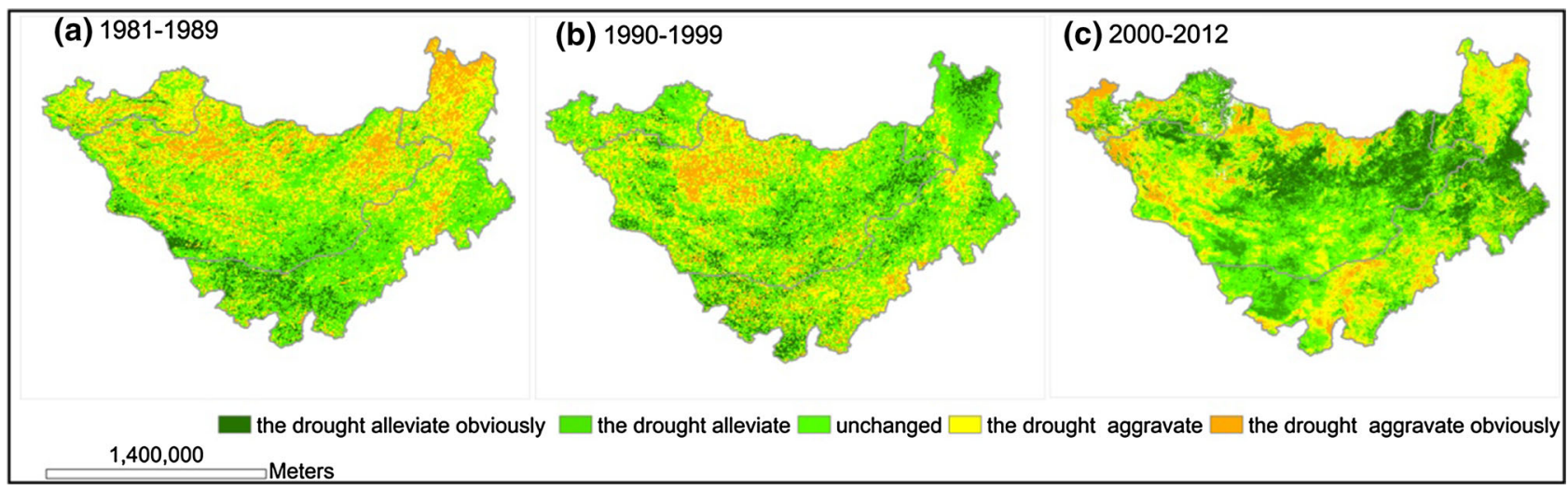

Figure 9. Variations (slope) of TVDI in different periods.

Table 4. The area of the changed TVDI in the Mongolian Plateau in three periods $\left(\times 10^{4} \mathrm{~km}^{2}\right)$.

\begin{tabular}{|c|c|c|c|c|c|c|}
\hline Period & $\begin{array}{c}\text { TVDI } \\
\text { variation } \\
\text { range }\end{array}$ & $\begin{array}{l}\text { Drought } \\
\text { aggravate } \\
\text { obviously } \\
<-0.2\end{array}$ & $\begin{array}{l}\text { Drought } \\
\text { aggravate } \\
{[-0.2,-0.005]}\end{array}$ & $\begin{array}{l}\text { Unchanged } \\
{[-0.005,0.005]}\end{array}$ & $\begin{array}{l}\text { Drought } \\
\text { alleviate } \\
{[0.005,0.2]}\end{array}$ & $\begin{array}{l}\text { Drought } \\
\text { alleviate } \\
\text { obviously } \\
>0.2\end{array}$ \\
\hline \multirow[t]{4}{*}{ 1981-1989 } & The Plateau & 25.94 & 77.53 & 105.33 & 62.34 & 26.24 \\
\hline & Inner Mongolia & 7.69 & 34.34 & 40.29 & 20.76 & 7.19 \\
\hline & Mongolia & 12.64 & 36.18 & 57.43 & 35.41 & 16.70 \\
\hline & Tuva & 5.61 & 7.01 & 7.61 & 6.17 & 2.35 \\
\hline \multirow[t]{4}{*}{ 1990-1999 } & The Plateau & 29.93 & 77.67 & 96.25 & 69.15 & 24.37 \\
\hline & Inner Mongolia & 7.95 & 25.32 & 35.89 & 29.96 & 11.12 \\
\hline & Mongolia & 20.59 & 44.67 & 47.51 & 33.46 & 12.12 \\
\hline & Tuva & 1.38 & 7.67 & 12.84 & 5.72 & 1.12 \\
\hline \multirow[t]{4}{*}{ 2000-2012 } & The Plateau & 46.78 & 92.52 & 91.34 & 51.75 & 14.98 \\
\hline & Inner Mongolia & 14.51 & 29.85 & 33.61 & 24.25 & 8.02 \\
\hline & Mongolia & 27.10 & 49.75 & 49.99 & 25.14 & 6.37 \\
\hline & Tuva & 5.16 & 12.91 & 7.73 & 2.35 & 0.58 \\
\hline
\end{tabular}

the grassland of west and middle Mongolia, and the meadow is mainly distributed in this area. It could reveal that, overgrazing in this area resulted in the decrease of vegetation coverage, which would also lead to the decrease of soil moisture, and the occurrence of drought. Table 4 shows that during 1981-2012, the alleviated drought area is averagely about $82.94 \times 10^{4} \mathrm{~km}^{2}$ and the aggravated drought area is about $116.78 \times 10^{4} \mathrm{~km}^{2}$. In the period of 2000-2012, the aggravated drought area was the largest $\left(139.30 \times 10^{4} \mathrm{~km}^{2}\right)$, but it was the smallest in 1981-1989 $\left(103.46 \times 10^{4} \mathrm{~km}^{2}\right)$. It would indicate that, the drought aggravated in the Mongolian Plateau during 1981-2012.

\subsubsection{The temporal development of the aridification}

From 1981 to 2012, the dry level area (annually $130.94 \times 10^{4} \mathrm{~km}^{2}, 44.03 \%$ ) accounted the largest area, followed by the normal level (annually $83.18 \times 10^{4} \mathrm{~km}^{2}, 27.97 \%$ ), the wet level (annually $43.57 \times 10^{4} \mathrm{~km}^{2}, 14.65 \%$ ) was the third largest, the extremely dry (annually $22.24 \times 10^{4} \mathrm{~km}^{2}, 7.48 \%$ ) and extremely wet levels (annually $17.44 \times 10^{4} \mathrm{~km}^{2}$, $5.86 \%$ ) were the smallest. On average, $51.51 \%$ of the plateau suffered by drought, indicating that drought was widespread in this area, and was serious in some periods. The area proportion of every level varied in different years (figure 10). Generally, from 1981 to 1992, the dry and extremely dry level experienced a fluctuated increase $\left(116.4 \times 10^{4}\right.$ $\left.142.3 \times 10^{4} \mathrm{~km}^{2}\right)$; the wet and normal levels showed a slightly fluctuating decrease; the extremely wet level basically remained unchanged. The results above indicated an obvious aridification in the Mongolian Plateau during 1981-2012. Li and Liu (2012) also pointed that in the 21st century, the extremely-dry and dry-area would show an obvious increase trend. Moreover, studies explored that 


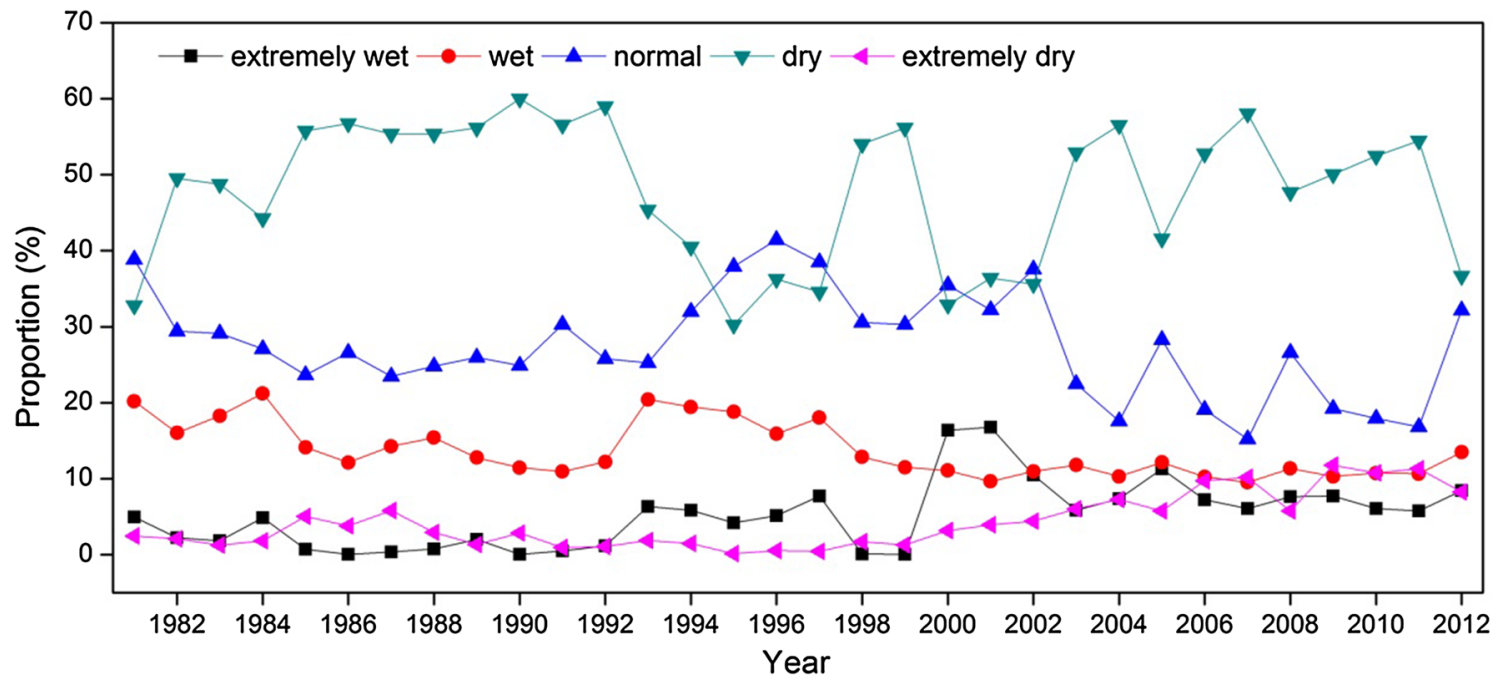

Figure 10. The annual area proportion of the different TVDI levels.
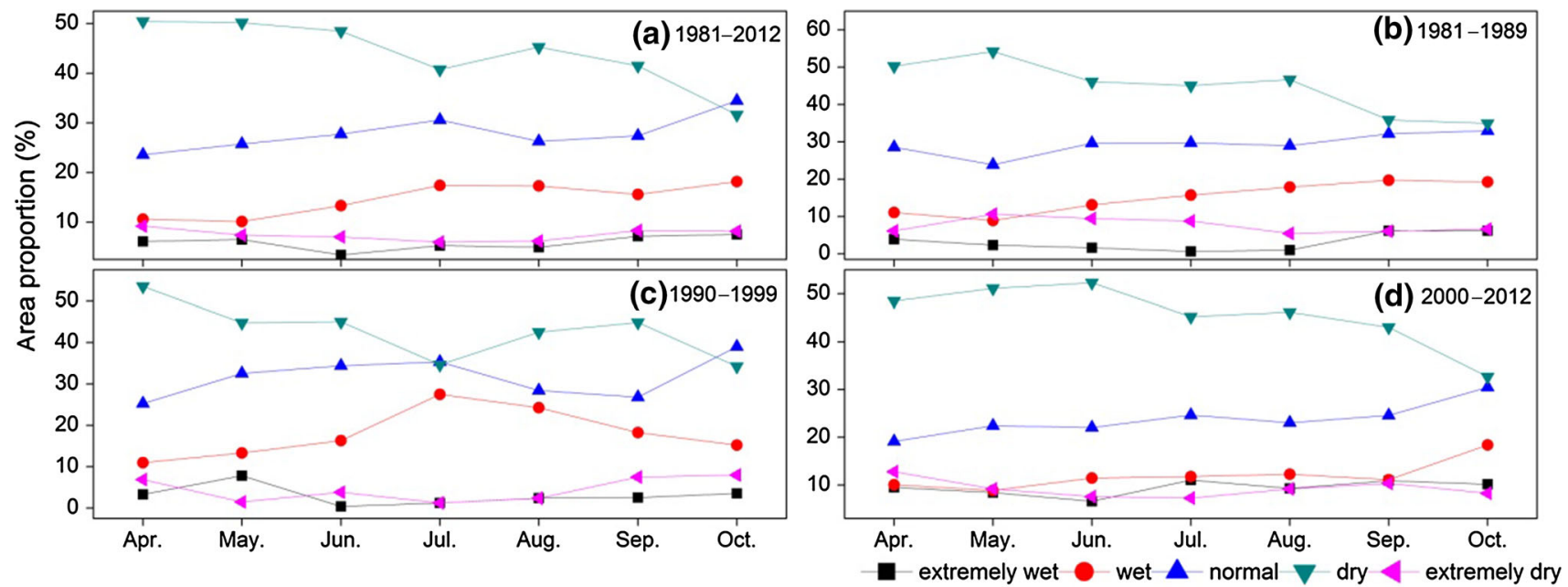

Figure 11. The monthly changes for the area proportion in different TDVI levels in different periods.

the snow cover in the Mongolian Plateau decreased after 2000 (Sa et al. 2012). The decreased snow cover would result in the decreased runoff, which may bring drought.

The results indicate that in one growth season, the area proportion of every drought level varied (figure 11). During the period of 1981-1999 and 2000-2012, it showed a similar variation tendency in one growth season: the extremely wet, wet and normal area increased slightly from April to August, and decreased in September and October. In April, drought was widely distributed in the Plateau. From May to August, with the increasing temperature and precipitation, vegetation begins to sprout and grow, the soil moisture and humid area kept on increasing, and the aridification appeared alleviated. In September and October, with the end of rainy season and growth season, the precipitation decreased, the dry and extremely dry levels showed a slight increase. But comparing with April, drought in September and October was lighter. Although there was drought during the growth season, drought during the early growth season was more serious than that at the end of growth season. In the beginning of growth season, more water is needed for the vegetation germination, but the precipitation is relatively low, which would be responsible for these results.

\subsection{The variation of the aridification in the land use/land cover}

Studies showed that, there are differences of soil moisture in different LUCC (Fu et al. 1999; Huang et al. 2005; Wang et al. 2010; Rahimzadeh et al. 2013). Plant growth status is affected by the soil 
Table 5. The area and proportion of every LUCC type in the Mongolian Plateau $\left(\times 10^{4} \mathrm{~km}^{2}\right)$.

\begin{tabular}{|c|c|c|c|c|c|c|}
\hline \multirow[b]{2}{*}{ Types } & \multicolumn{2}{|r|}{2001} & \multicolumn{2}{|r|}{2005} & \multicolumn{2}{|r|}{2009} \\
\hline & Area & $\begin{array}{c}\text { Proportion } \\
(\%)\end{array}$ & Area & $\begin{array}{c}\text { Proportion } \\
(\%)\end{array}$ & Area & $\begin{array}{c}\text { Proportion } \\
\text { (\%) }\end{array}$ \\
\hline Grassland & 134.38 & 45.24 & 161.49 & 54.37 & 157.02 & 52.86 \\
\hline Bare land & 88.45 & 29.78 & 74.03 & 24.92 & 79.03 & 26.61 \\
\hline Forest & 22.90 & 7.72 & 23.41 & 7.87 & 26.23 & 0.0884 \\
\hline Shrub land & 19.10 & 6.43 & 12.84 & 4.32 & 11.65 & 3.92 \\
\hline Cropland & 29.79 & 10.03 & 22.99 & 7.74 & 20.8 & 7.00 \\
\hline Construction land & 0.42 & 0.14 & 0.42 & 0.14 & 0.42 & 0.14 \\
\hline Wet land & 0.06 & 0.02 & 0.12 & 0.04 & 0.19 & 0.07 \\
\hline Others & 1.94 & 0.64 & 1.72 & 0.60 & 1.69 & 0.56 \\
\hline
\end{tabular}

moisture; meanwhile, the distribution of soil moisture could also be affected by the LUCC types and vegetation cover (Fu et al. 1999; Chen et al. 2006). The Mongolian Plateau is mainly covered by grassland and bare land (figure 2; table 5). The grassland is mainly distributed in the western, northern, and southeastern regions in the plateau $(50.82 \%$ of the total area). The bare land is mainly distributed in the southwestern regions (27.10\%). In the north plateau, the forest $(8.14 \%)$ was wildly spread. Shrub land accounted for about $4.89 \%$. Crop land (8.35\%) mainly distributed in the inner Mongolia.

The TVDI was expected to reveal the water deficit for the region from low NDVI (bare soil) to high (full vegetation cover) NDVI values. The results show that the soil moisture was higher in forest and shrub land, and lower in grassland, bare land, construction land and crop land (figures 2 and 8). Forest and shrub land were dominated by the wet and extremely wet levels, followed by the normal level. In forest, the wet and extremely wet area averagely accounted for about 81.98 and $17.50 \%$ of the area respectively, the dry and extremely dry area only accounted for about $0.52 \%$. In shrub land, the proportion of the wet/extremely wet, normal, and the dry/extremely dry area account for about $61.48,16.76$ and $23.95 \%$, respectively.

The soil moisture was very high in the forest, and with almost no drought. In shrub land, the dry/extremely dry area accounted more proportion than that in forest, suggesting the occurrence of some droughts in the shrub land. The dry/ extremely dry area accounted for the largest proportion in grassland, bare land and construction land, the normal level accounted for the second largest proportion. The TVDI-level allocation presented obvious differences in different LUCC types; aridification was the most serious in bare land (about $80 \%$ of the area suffers drought), followed by construction land, and grassland. In construction land and grassland, about $50 \%$ of the area suffered drought. As the results obtained in section 3.1, the TVDI was found to be in close negative agreement with precipitation and soil moisture, therefore it can be inferred that changes in the TVDI are dependent on the water status in the plateau. As cumulative precipitation for the growing season is higher in forest and shrub land than other LUCC types, it could be concluded that forest and shrub land have better water availability.

The dry/extremely dry area proportion in different LUCC types had few annual changes (figure 12), but it had the usual monthly changes, which mainly occurred between grassland and bare land in September and October. From April to August, the dry/extremely dry area proportion in grassland was obviously larger than that in bare land, and in September and October, the trend was the inverse. These results indicate that, at the end growth season, drought is relieved in some areas of the grassland. The reasons for these results would be considered in two parts: (1) at the end of growth season, the drastically reduced precipitation result in more severe drought in bare land; (2) overgrazing may lead to the appearance of bare area in grassland, and the increasing soil moisture evaporation. Therefore, in the early and peak of growth season, short-term drought would occur in some area of grassland. However, there are no explicit data to explain this phenomenon, the causes and mechanism of this phenomenon would require an in-depth study. 


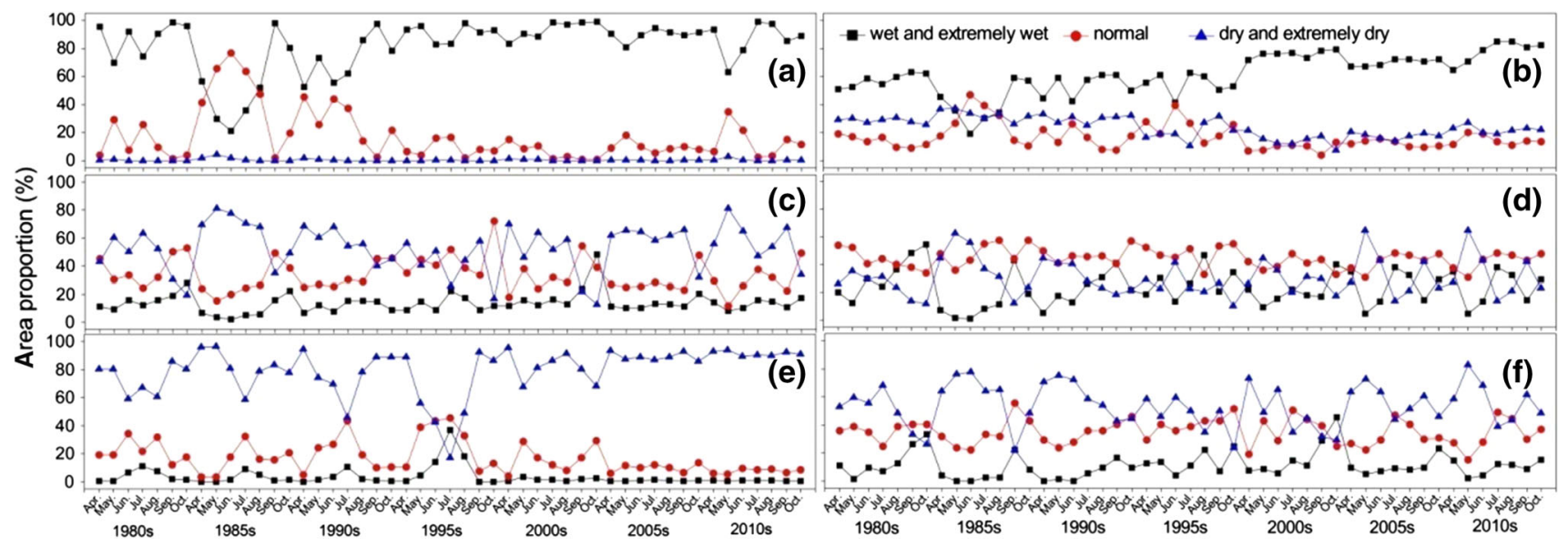

Figure 12. The area proportion of different drought levels in every LUCC (a) forest; (b) shrub; (c) grassland; (d) cropland; (e) bare land; and (f) construction land.

\section{Conclusion}

Based on the general Ts-NDVI space and TVDI, monitoring the long-term spatio-temporal changes of soil moisture is an effective method. If the dry/ wet edge in the single time space is obviously different from that in the general space, the general space extracted from years of remote sensing data would be more stable, and the inverted results of the general space would also be more meaningful and more close to the theoretical value. Otherwise, there would be no difference between the inverted results of the single time space and the general space.

The TVDI calculated in the paper is expected to show the water deficit for the region from low (bare soil) to high (full vegetation cover) NDVI values, and it is found to be in close negative agreement with precipitation and soil moisture, changes in the TVDI are dependent on the water status in the study area.

There was significant negative relationship between TVDI and the $10-\mathrm{cm}$ soil moisture and the cumulative precipitation. In the Mongolian Plateau, the annual precipitation would be a significant natural factor to affect the soil moisture, which would affect the drought and aridification for a period. During 1981-2012, the plateau was dominated by dry and extremely dry level, on averaged $51.51 \%$ of the plateau suffered by drought, and there was an obvious aridification in the plateau. The excessive development, overgrazing, the disorder of urban sprawl would bring decreased vegetation cover and land degradation. Besides the affection of human beings, the decreased snow cover and vegetation cover would also bring drought and aridification.

\section{Acknowledgements}

The authors are grateful for the support by the National Key Basic Research and Development Program (973 Program) (Grant No. 2013CB42990504), the Key Deployment Project of the Chinese Academy of Sciences (Grant No. KZZD-EW-08), the youth fund from the National Natural Science Foundation of China (Grant No. 41501477), the foundation of Chinese Academy of Forestry (Grant No. CAFYBB2016QB021), the special scientific research fund of forestry public welfare profession of China (Grant No. 201404304).

\section{References}

Anyamba A and Tucker C J 2005 Analysis of Sahelian vegetation dynamics using NOAA-AVHRR NDVI data from 1981-2003; J. Arid Environ. 63 596-614.

Bao G, Qin Z H and Bao Y H et al. 2013 Spatial-temporal changes of vegetation cover in Mongolian Plateau during 1982-2006; J. Desert Res. 33 918-927.

Becker F and Li Z L 1990 Towards a local split window method over land surface; Int. J. Remote Sens. 11369 393.

Bi L G, Yin S and Bao Y L et al. 2011 Research on the drought during the vegetation growth period of inner Mongolia based on TVDI; J. Anhui. Sci. 39 5945-5948.

Caccamo G, Chilsholm L A and Bradstock R A et al. 2011 Assessing the sensitivity of MODIS to monitor drought in high biomass ecosystems; Remote Sens. Environ. 115 2626-2639.

Carlson T 2007 An overview of the triangle method for estimating surface evapotranspiration and soil moisture from satellite imagery; Sensors 7 1612-1629.

Chandrasekar K and Sai M V R S 2015 Monitoring of lateseason agricultural drought in cotton-growing districts of Andhra Pradesh state, India, using vegetation, water and soil moisture indices; Nat. Hazards 75 1023-1046. 
Chen X L, Zhao H M, Li P X and Yin Z Y 2006 Remote sensing image-based analysis of the relationship between urban heat island and land use/cover changes; Remote Sens. Environ. 104 133-146.

Cihlar J, Huang L Y and Li Z Q et al. 1997 multitemporal, multichannel AVHRR datasets for land biosphere studies - Artifacts and corrections; Remote Sens. Environ. 6035 57.

Dogan S, Berkta A and Singh V P 2012 Comparison of multi-monthly rainfall-based drought severity indices with application to semi-arid Konya closed basin, Turkey; $J$. Hydrol. 4 255-268.

Du L T, Tian J and Tao Y et al. 2013 A comprehensive drought monitoring method integrating MODIS and TRMM data; Int. J. Appl. Earth. Obser. Geoinfo. 23 245253.

Fensholt R and Sandholt I 2003 Derivation of a shortwave infrared water stress index from MODIS near- and shortwave infrared data in a semiarid environment; Remote Sens. Environ. 87 111-121.

Frey C M, Kuenzer C and Dech S 2012 Quantitative comparison of the operational NOAA-AVHRR LST product of DLR and the MODIS LST product V005; Int. J. Remote Sens. 33 7165-7183.

Fu B J, Cheng L D and Ma K M 1999 The effect of land use change on the regional environment in the Yang Juangou catchment in the Loess Plateau of China; Acta Geogr. Sin. 5 241-246.

Gallo K, Lei J and Reed B et al. 2004 Comparison of MODIS and AVHRR 160 day normalized difference vegetation index composite data; Geophys. Res. Lett. 31 73-95.

Gao Z, Gao W and Chang N B 2011 Integrating temperature vegetation dryness index (TVDI) and regional water stress index (RWSI) for drought assessment with the aid of LANDSAT TM/ETM+ images; J. Appl. Earth Obser. Geoinform. 13 495-503.

Goetz S J 1997 Multi-sensor analysis of NDVI, surface temperature and biophysical variables at a mixed grassland site; Int. J. Remote Sens. 18 71-94.

Guo L B 2010 Analyses the soil moisture of Mongolia Plateau with MODIS-TVDI Model and AMSR-E data; The master degree paper of Inner Mongolia Normal University.

Han L J, Atsushi T and Mitsuru T 2011 Effect of frozen ground on dust outbreaks in spring on the eastern Mongolian Plateau; Geomorphology 129 412-416.

Heim R R 2002 A review of twentieth-century drought indices used in the United States; Bull. Am. Meteor. Soc. 83 1149-1165.

Holben B 1986 Characteristics of maximum-value composite images from temporal AVHRR data; Int. J. Remote Sens. 4 1417-1434.

Huang Y L, Chen L D, Fu B J and Wang Y L 2005 Spatial pattern of soil water and its influencing factors in a gully catchment of the Loess Plateau; J. Nat. Res. 20 483-492.

Huber S and Fensholt R 2011 Analysis of teleconnections between AVHRR-based sea surface temperature and vegetation productivity in the semi-arid Sahel; Remote Sens. Environ. 115 3276-3285.

Keyantash J and Dracup J 2002 The quantification of drought: An evaluation of drought indices; Bull. Am. Meteor. Soc. 83 1167-1180.
Kogan F N 1995 Application of vegetation index and brightness temperature for drought detection; Adv. Space Res. 1 91-100.

Li X Z and Liu X D 2012 A modeling study on drought trend in the Sino-Mongolian arid andd semiarid regions in the 21st Century; Arid Zone Res. 29 262-272.

Li X Z, Liu X D and Ma Z G 2004 Analysis on the drought characteristics in the main arid regions in the world since recent hundred-odd years; Arid Zone Res. $2197-$ 103.

Liu H Z, Wang B M and Fu C B 2008 Relationships between surface albedo, soil thermal parameters and soil moisture in the semi-arid area of Tongyu, Northeastern China; $A d v$. Atmos. Sci. 25 757-764.

Liu L L, Liu L Y and Hu Y 2012 Comparative analysis of global vegetation phenology based on AVHRR and MODIS; Remote Sens. Technol. Appl. 27 754-762.

Liu Y L, Zhuang Q H and Chen M et al. 2013 Response of evapotranspiration and water availability to changing climate and land cover on the Mongolian Plateau during the 21st century; Global Planet. Change 108 8599.

Ma Z G, Huang G G and Gan W G et al. 2005 Multiscale temporal characteristics of the dryness/wetness over northern China during the last century; Chin. J. Atmos. Sci. $29671-681$.

Malo A R and Nicholson S E 1990 A study of rainfall and vegetation dynamics in the African Sahel using normalized difference vegetation index; J. Arid Environ. 19 1-24.

Mcffters S K 1996 The use of the normalized difference water index (NDWI) in the delineation of open water features; Int. J. Remote Sens. 17 1425-1432.

NASA-EOS 2006 NASA Earth observing system data gateway [online]; http://delenn.gsfc.nasa.gov/ imswww/pub/ imswelcome/

Parinaz R B, Kenji O and Yo S 2012 Comparative evaluation of the Vegetation Dryness Index (VDI), the Temperature Vegetation Dryness Index (TVDI) and the improved TVDI (iTVDI) for water stress detection in semi-arid regions of Iran; ISPRS J. Photogramm. Remote Sens. 68 $1-12$.

Price J C 1990 Using spatial context in satellite data to infer regional scale evapotranspiration; IEEE Trans. Geosci. Remote Sens. 28 940-948.

Qi S H 2004 Drought monitoring models with remote sensing and spatio-temporal characteristics of drought in China; $\mathrm{PhD}$ thesis of Chinese Academy of Sciences. Phd

Rahimzadeh B P, Omasa K and Shimizum Y 2012 Comparative evaluation of the Vegetation Dryness Index (VDI), the Temperature Vegetation Dryness Index (TVDI) and the improved TVDI (iTVDI) for water stress detection in semi-arid regions of Iran; ISPRS J. Photogramm. Remote Sens. 68 1-12.

Rahimzadeh P B, Berg A A and Champagne C et al. 2013 Estimation of soil moisture using optical/thermal infrared remote sensing in the Canadian Prairies; ISPRS J. Photogramm. Remote Sens. 83 94-103.

Rhee J Y, Im J and Carbone G J 2010 Monitoring agricultural drought for arid and humid regions using multisensor remote sensing data; Remote Sens. Environ. 114 $2875-2887$ 
Sa C L, Liu G X and Bao G et al. 2012 The spatial and temporal changes of snow cover of the Mongolian Plateau in Recent 10 years; J. Inner Mong. Norm. Univvers. 41 $531-535$

Sandholt I, Rasmussen K and Andersen J 2002 A simple interpretation of the surface temperature/vegetation index space for assessment of surface moisture status; Remote Sens. Environ. 79 213-224.

Seneviratne S I, Pal J S and Eltahir E A B et al. 2002 Summer dryness in a warmer climate: A process study with a regional climate model; Clim. Dyn. 20 69-85.

Shi C and Liu X D 2012 Continent drought characteristics over the Eastern Hemisphere from 1947 to 2006: Analyses based on the SPEI dataset; J. Desert Res. 6 16911701.

Shi Y F and Shen Y P 2002 Preliminary study on signal impact and foreground of climate shift from warm-dry to warm-humid in northwest China; J. Glaciol. Geocryol. 24 219-223.

Shu Y Q, Stisen S, Jensen K H and Sandholt I 2011 Estimation of regional evapotranspiration over the North China Plain using geostationary satellite data; Int. J. Appl. Earth Obser. Geoinfo. 13 192-206.

Sobrino J A, Coll and Caselles V 1991 Atmospheric correction for land surface temperature using NOAA-11 AVHRR channel 4 and 5; Remote Sens. Environ. 3819 34.

Steven M Q and Srinivasan G 2010 Evaluating the utility of the Vegetation Condition Index (VCI) for monitoring meteorological drought in Texas; Agric. Forest Meteorol. $150330-339$.

Stow D, Daeschner S and Hope A et al. 2003 Variability of the seasonally integrated normalized difference vegetation index across the north slope of Alaska in the 1990s; Int. J. Remote Sens. 24 1111-1117.

Sun and Kafatos 2007 Note on the NDVI-LST relationship and the use of temperature-related drought indices over North America; Geophys. Res. Lett. 34 497-507

Sun H, Zhao X, Chen Y et al. 2013 A new agricultural drought monitoring index combining MODIS NDWI and day-night land surface temperatures: A case study in China; Int. J. Remote Sens. 34 8986-9001.

Tian H, Wang C H and Wen J et al. 2012 Soil moisture estimation over an arid environment in Mongolia from passive microwave remote sensing based on a simplified parameterization method; Chinese J. Geophys. 55 415-427.

Tong S Q, Liu G X and Bao Y H et al. 2014 The drought monitoring research in Mongolian Plateau during 19822006; Info. Technol. Risk Anal. Crisis Response, pp. 169176.

Tucker C J, Holben B N, Elgin J H and Mcmurtrey J E 1981 Remote-sensing of total dry-matter accumulation in winter-wheat; Remote Sens. Environ. 11 171-189.
Vicente-Serrano S M, Cuadrat-Prats J M and Romo A 2006 Aridity influence on vegetation patterns in the middle Ebro Valley (Spain): Evaluation by means of AVHRR images and climate interpolation techniques; J. Arid Environ. 66 353-375.

Wang C, Qi S, Niu Z and Wang J 2004 Evaluating soil moisture status in China using the temperature-vegetation dryness index (TVDI); Canadian J. Remote Sens. $30671-$ 679.

Wang D W, Zhao J and Yin D et al. 2013 Potential vegetation dynamic analysis of spatial and temporal characteristics of inner Mongolia's geographical pattern in recent 50 a; Pratacul. Sci. 30 1167-1173.

Wang H, Li X B and Long H L et al. 2010 Monitoring the effects of land use and cover type changes on soil moisture using remote-sensing data: A case study in China's Yongding River basin; Catena. 82 135-145.

Wang L, Zhen L and Liu X L et al. 2008 Comparative studies on climate changes and influencing factors in central Mongolian Plateau region; Geogr. Res. 1171-180.

Wang W and Feng Z D 2013 Holocene moisture evolution across the Mongolian Plateau and its surrounding areas: A synthesis of climatic records; Earth-Sci. Rev. 12238 57.

$\mathrm{Xu}$ H 2006 Modification of normalized difference water index (NDWI) to enhance open water features in remotely sensed imagery; Int. J. Remote Sens. 273025-3033.

Xue Y K 1996 The impact of desertification in the Mongolian and inner Mongolian grassland on the regional climate; $J$. Climate 9 2173-2189.

Yang X H, Zhuo G and Luo B 2011 On MODIS data based drought monitoring in Northwest China; Pratac. Sci. 28 1420-1426.

Yu H Y, Lue D L E and Xu J C 2010 Winter and spring warming result in delayed spring phenology on the Tibetan Plateau; Proc. Nat. Acad. Sci. 107 22,15122,156 .

Yu M, Cheng M H and Liu H 2011 An improvement of the land surface temperature-NDVI space drought monitoring method and its applications; Acta Meteorol. Sin. 69 922931.

Zhang A and Jia G 2013 Monitoring meteorological drought in semiarid regions using multi-sensor microwave remote sensing data; Remote Sens. Environ. 134 12-23.

Zhang F, Zhang L W and Wang X Z et al. 2013 Detecting agro-droughts in southwest of China using MODIS satellite data; J. Integra. Agric. 12 159-168.

Zhang J Y, Dong W J and Fu C B 2005 The effects of the degradation in northern China and southern Mongolia on the regional climate; Chin. Sci. Bull. 50 53-58.

Zhang X Y, Zhang G Y and Zhu G H et al. 1996 Elemental tracers for Chinese source dust; Science in China (Series D) $395512-521$. 